\title{
A comparative study of superiorly based circumferential tympanomeatal flap tympanoplasty with anteriorly anchoring flap tympanoplasty in large, subtotal, and anterior tympanic membrane central perforations in chronic suppurative otitis media of mucosal type
}

\author{
Amitkumar Rathi, Vinod Gite*, Sameer Bhargava, Neeraj Shetty
}

Department of ENT, HBTMCH and Dr. R.N. Cooper Hospital, Mumbai, Maharashtra, India

Received: 11 November 2017

Revised: 23 December 2017

Accepted: 25 December 2017

\section{*Correspondence:}

Dr. Vinod Gite,

E-mail: drvinodgite@gmail.com

Copyright: (C) the author(s), publisher and licensee Medip Academy. This is an open-access article distributed under the terms of the Creative Commons Attribution Non-Commercial License, which permits unrestricted non-commercial use, distribution, and reproduction in any medium, provided the original work is properly cited.

\begin{abstract}
Background: The main objective of the study was to assess and compare the graft uptake, hearing improvement, complications in large, subtotal, and anterior moderate perforations by each technique viz; superiorly based circumferential tympanomeatal flap tympanoplasty (STT)/full cuff and anterior anchoring flap tympanoplasty (AAT)/anterior tucking.

Methods: In our study of 30 cases age group in the range of 10 years to 60 years. The mean air bone gap for the 8 patients with anterior moderate perforation was $31.75 \mathrm{db}$, for 17 patients with large central perforations was $38.75 \mathrm{db}$ and for 5 patients with subtotal perforations was $41.4 \mathrm{db}$.

Results: Mean air bone gap closure after 3 months of surgery in the STT group was $21.4 \mathrm{db}$ while that after $6 \mathrm{months}$ of the surgery for the same group was $22.06 \mathrm{db}$. Mean air bone gap closure after 3 months of surgery in the AAT group was $18.2 \mathrm{db}$ while that after 6months of the surgery for the same group was $18.73 \mathrm{db}$.

Conclusions: Comparing the air bone gap closure in patients who underwent surgery by AAT and STT technique we found that there is no statistical difference. Both techniques (viz: superiorly based circumferential tympanomeatal flap tympanoplasty and anteriorly anchoring flap tympanoplasty) can be used for the repair of large, subtotal, and anterior tympanic membrane central perforations in chronic suppurative otitis media of mucosal type.
\end{abstract}

Keywords: CSOM, Full cuff, Anterior tucking

\section{INTRODUCTION}

Otitis media is an important and a highly prevalent disease of the middle ear and poses serious health problem worldwide especially in developing countries where large percentage of the population lack specialized medical care, suffer from malnutrition and live in poor hygienic environmental conditions. ${ }^{1}$

Myringoplasty, is an operation performed to repair or reconstruct the tympanic membrane. ${ }^{2}$ It is also known as tympanoplasty type I, where peroperatively middle ear structures are exposed and are checked for functional integrity. ${ }^{3}$ Three main approaches are used in tympanoplasty: transcanal, endaural, and postauricular. Two classic methods for reconstruction of a TM perforation have been used: the underlay and the overlay graft techniques. Each of these approaches and techniques has its advantages and disadvantages. ${ }^{4,5}$

Underlay technique is widely used and relatively simple to perform as the graft is placed entirely medial to the 
remaining drum and malleus. In the overlay technique, the graft is placed lateral to the annulus and any remaining fibrous middle layer. The overlay technique is more challenging and typically reserved for total perforations, anterior perforations, or failed underlay surgery. ${ }^{6}$ The anterior and subtotal tympanic membrane perforation continues to be one of the greatest problems in middle ear surgery. It has been shown that one of the most important factors in the success of myringoplasty is the size and position of the perforation and it has been noted that the repair of anterior and subtotal perforations is less likely to be successful compared with the repair of small posterior perforations. It is generally accepted that the method used for the repair of posterior perforations may not be appropriate for either anterior or subtotal perforations. If the perforation is in the anterior half of the tympanic membrane or if the perforation is subtotal, then underlay tympanoplasty may fail because the anterior edge of the graft falls away from and fails to adhere to the anterior remnant of the tympanic membrane. Although overlay technique has higher success rate for the reconstruction of anterior large or subtotal tympanic membrane perforations, serious complications including anterior angle blunting, graft lateralization, epithelial pearls and delayed healing may occur. The most common area of tympanoplasty failure when repairing total perforations is the anterosuperior area for several reasons including lack of graft support and less vascularity, with a greater risk of reperforation. ${ }^{7}$ Added to these cases are marginal perforations, causing the closure rates to drop even further.

In order to achieve greater success with graft uptake, hearing improvement, and prevention of complications, there are many modifications in underlay technique. In this study we have taken two of the modified techniques for correcting anterior moderate, large and subtotal tympanic membrane central perforations in chronic otitis media of mucosal type. The selected techniques are 1) Superiorly based circumferential tympanomeatal flap tympanoplasty; 2) Anteriorly anchoring flap tympanoplasty.

\section{Aims and objectives}

1. To assess and compare the graft uptake in large, subtotal, and anterior moderate perforations by each technique (viz; superiorly based circumferential tympanomeatal flap tympanoplasty and anterior anchoring flap tympanoplasty).

2. To assess and compare the hearing improvement by each of the technique.

3. To assess and compare the complications produced by each of the technique.

\section{METHODS}

Study design: Prospective comparative study

Study period : October 2013 - June 2015

\section{Sample size}

In the literature of all the prospective studies reviewed, we found that the sample sizes varied from a minimum of 20 to a maximum of 110. Hence, we (based on feasibility) decided to study a total of 30 cases.

\section{Study population}

The study population comprised of 30 subjects (15 subjects of each group viz STT and AAT respectively).

\section{Inclusion criteria}

Inclusion criteria were chronic suppurative otitis media of tubotympanic type with anterior, large and subtotal perforations; age group of patients between 10 to 60 years of both the sexes.

\section{Exclusion criteria}

Exclusion criteria were cases of chronic suppurative otitis media of atticoantral type; cases of chronic suppurative otitis media with ossicular discontinuity; cases of chronic suppurative otitis media with extensive disease (cholesteatoma) requiring exteriorizing procedure like modified radical mastoidectomy; cases with sensory neural hearing loss.

After the approval from ethics committee, patients undergoing surgery for chronic suppurative otitis mediamucosal type at Dr. R. N. Cooper Municipal General Hospital, Vile Parle (west), Mumbai and falling into the inclusion criteria were chosen for the study. Patients with ear discharge were initially treated conservatively and were included in the study when their ear became dry for at least 6 weeks. ${ }^{8}$

The cases of chronic suppurative otitis media with hearing loss were first diagnosed by examination (otomicroscopy) and investigations (Tuning fork test and pure tone audiometry). All patients participating in the study underwent an audiometric assessment before surgery and at 3 months and 6 months after surgery. In accordance with 1995 guidelines of American academy of otolaryngology- head and neck surgery (AAO-HNS) pure tone audiometry using the frequencies $500 \mathrm{~Hz}, 1000$ $\mathrm{Hz}, 2000 \mathrm{~Hz}$, and $4000 \mathrm{~Hz}$ were plotted and air bone gap was calculated with a pure tone-bone conduction averages at $500 \mathrm{~Hz}, 1000 \mathrm{~Hz}$, and $2000 \mathrm{~Hz}$. Hearing results were assessed by comparing pre-operative and post-operative pure tone averages over the above three frequencies as well as closure of the air-bone gap at 3 months and 6 months of surgery.

The study subjects/subject's guardians or parents (in cases of minor) were first administered an informed consent form (Annexure 1). After explaining the treatment options to the subjects in detail written consent 
were obtained from those who agreed to participate in the study.

For every individual consenting to participate in the study, a case record form was filled as (Annexure 2). Randomization was done by draw of lots.

The surgery was done under local or general anaesthesia by postaural route. After raising the tympanomeatal flap by either of the technique, status of the ossicular chain was assessed. Temporalis fascia was used to close the perforation by underlay technique.

\section{Surgical technique}

The surgical techniques used by us in our study are as follows;

\section{A. superiorly based circumferential tympanomeatal flap} tympanoplasty

- Canal incision given radially from 12 'O clock from medial to lateral, while a second circumferential incision from 1 ' $O$ clock lateral to the annulus (approximately $6 \mathrm{~mm}$ lateral to annulus) extending circumferentially and joining 5'O clock radially.

- Elevation of circumferential tympanomeatal flap, which is superiorly based.

- Temporalis fascia graft is anchored under the handle of Malleus and reposited all around the bony annulus.

\section{B. Anteriorly anchoring flap tympanoplasty}

- Canal incisions: 12'O clock incision radially from medial to lateral over the canal other incision is taken from 6'O clock radially from medial to lateral these two incisions creates a posteriorly based tympanomeatal flap. Another incision circumferentially just lateral to the annulus (approximately $6 \mathrm{~mm}$ lateral to annulus) on the anterior canal wall from 1' $\mathrm{O}$ clock to $5^{\prime} \mathrm{O}$ clock creating an anterior canal flap taken.

- Posterior flap elevated and ossicles mobility checked.

- Temporalis fascia graft placed in an underlay fashion below the handle of malleus while the anterior edge of the graft is tucked under the anterior flap made initially tympanomeatal flap reposited.

\section{Statistical analysis}

Data was collected using case record forms and were entered on Microsoft excel spreadsheet. Given the normal distribution of values, differences between patients of two groups were assessed using a two-tailed, two-sample Student's t-test on Microsoft excel 2007. Differences between postoperative and preoperative results were analyzed with a paired t-test Microsoft excel 2007.
Categorical variables were studied with a chi-square test on open epi software.

\section{RESULTS}

Age

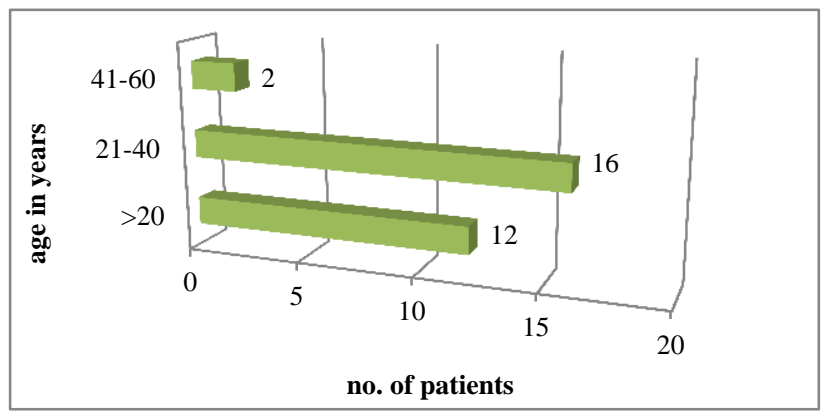

Figure 1: Showing age distribution for the whole study.

\section{Gender}

Male outnumbered females in our study, total of 16 males (53\%) and 14 females (47\%) participated in the study (Figure 2).

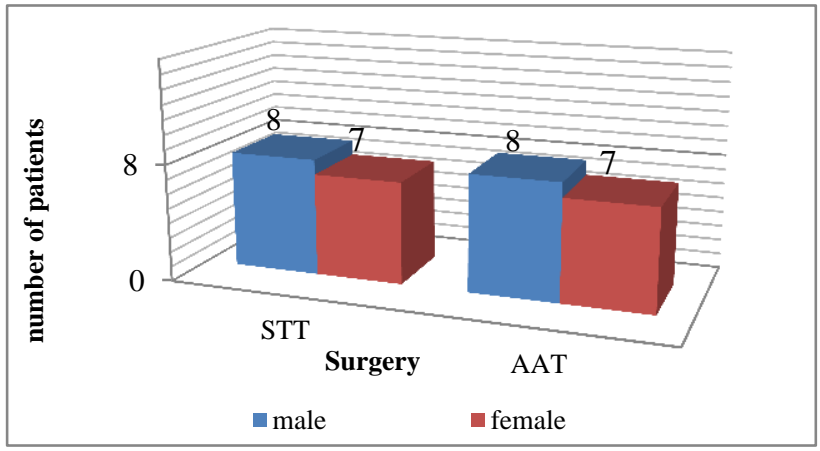

Figure 2: Showing gender distribution in the individual groups.

\section{Chief complaints}

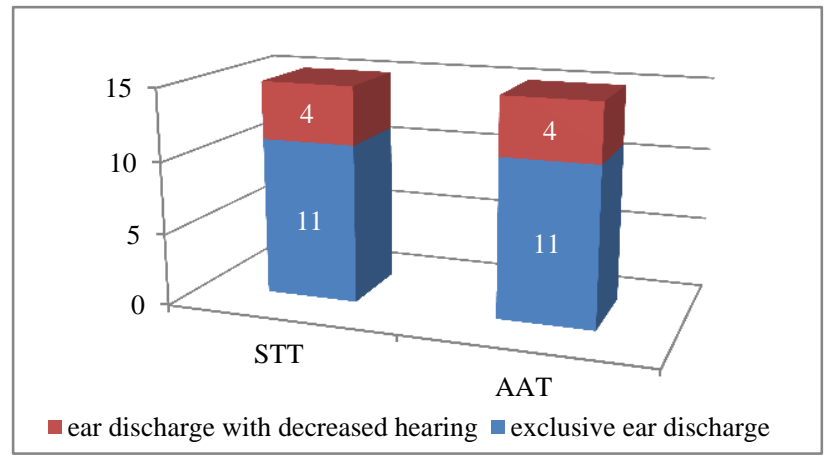

Figure 3: Showing distribution of the chief complaints in the individual groups. 


\section{Side of the diseased ear}

Involvement of right side of the ear was seen in 10patients $(33 \%)$ and left side in 20 patients $(67 \%)$.

\section{Comorbidity}

Out of all the patients 4 patients had co- morbities as hypertension and diabetes mellitus and HIV infection was seen in one patient.

\section{Mean air bone gap}

Comparing the mean air bone gap preoperatively of both the groups (AAT and STT) separately showed no statistical difference between both (Table 1).

Table 1: Showing pre surgery mean air bone gap in the individual groups.

\begin{tabular}{|lll|}
\hline Mean AB gap in db & $\begin{array}{l}\text { Pre surgery } \\
\text { (STT) }\end{array}$ & $\begin{array}{l}\text { Pre surgery } \\
\text { (AAT) }\end{array}$ \\
\hline Standard deviation & 4.87 & 35.6 \\
\hline P value & 0.124059993 & 6.31 \\
\hline
\end{tabular}

(Values: mean \pm S.D., $\mathrm{p}<0.05$ : significant, $\mathrm{P}>0.05$ : not significant).

Comparison between the mean air bone gaps of the patients operated by both the techniques at 3 months showed no statistically significant difference (Figure 4).

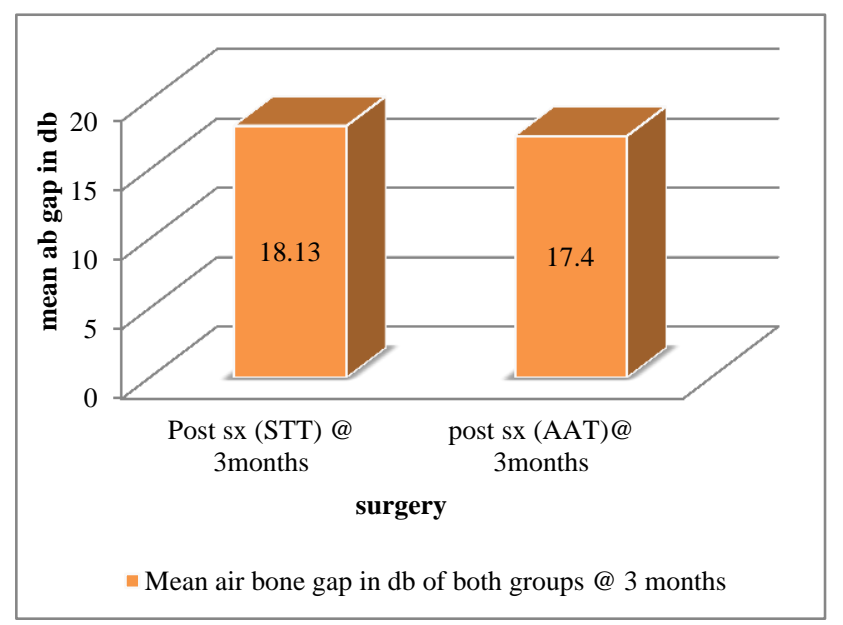

Figure 4: Comparison between post-surgery mean air bone gaps at 3 months between individual groups.

Comparing the mean air bone gap of the patients who got operated by STT technique and by AAT technique after 6 months shows no significant difference statistically (Figure 5).
The mean air bone gap closure of the patients operated by STT and AAT technique at 6 months of surgery shows no statistical difference (Table 2).

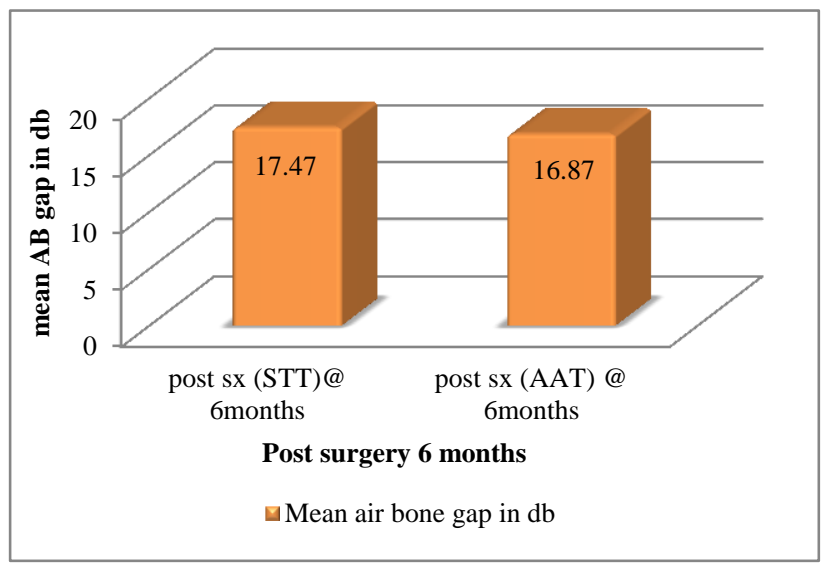

Figure 5: Comparison between post-surgery mean air bone gaps at 6 months between individual groups.

Table 2: Showing mean air bone gap closure post surgery at 6 months of individual groups.

\begin{tabular}{|lll|}
\hline & $\begin{array}{l}\text { Post surgery } \\
\text { STT (6months) }\end{array}$ & $\begin{array}{l}\text { Post surgery } \\
\text { AAT (6months) }\end{array}$ \\
\hline $\begin{array}{l}\text { Mean AB gap } \\
\text { closure in db }\end{array}$ & 22.07 & 18.73 \\
\hline $\begin{array}{l}\text { Standard } \\
\text { deviation }\end{array}$ & 4.15 & 5.05 \\
\hline P value & 0.058138 & \\
\hline
\end{tabular}

(Values: mean \pm S.D., $\mathrm{p}<0.05$ : significant, $\mathrm{P}>0.05$ : not significant).

\section{Complications}

In the entire study out of 30 patients 2 patients developed complication, this was a residual perforation after 6months of surgery (Table 3 ).

Table 3: Showing distribution of the complications in the individual groups.

\begin{tabular}{|c|c|c|c|c|}
\hline & & $\begin{array}{l}\text { Compli } \\
\text { (residur }\end{array}$ & $\begin{array}{l}\text { tions } \\
\text { perforat }\end{array}$ & \\
\hline & & Present & Absent & Total \\
\hline Surgery & STT & 1 & 14 & 15 \\
\hline (type) & AAT & 1 & 14 & 15 \\
\hline & total & 2 & 28 & 30 \\
\hline P value & 1 & & & \\
\hline
\end{tabular}

( $p<0.05$ : significant, $P>0.05$ : not significant).

Comparing the complications developed in the patients who underwent surgery by AAT and STT technique we found that there is no statistical difference in the development of complication. 


\section{DISCUSSION}

The main objective of myringoplasty has traditionally been the closure of the tympanic membrane perforation to prevent chronic infections and to make the ear safe. ${ }^{10}$ Consequently; the second objective is to improve the hearing loss which resulted due to perforation of the tympanic membrane. There is still no consensus about the optimal technique, which is often employed on the basis of the surgeon's preference and skills, and not on the type of the tympanic membrane perforation. ${ }^{11}$ In our study we compared two techniques of raising the tympanomeatal flaps in tympanoplasty viz superiorly based circumferential tympanomeatal flap, anterior anchoring flap. In our study these two modified techniques were used to close the anterior moderate, large and subtotal perforations of tympanic membrane in csom of mucosal type.

For this purpose, a prospective randomized study was done in which 30 patients with chronic suppurative otitis media (mucosal type) who were randomly allocated two groups- Group I (i.e. STT) comprising of 15 patients in whom superiorly based tympanomeatal flap tympanoplasty was done, Group II (i.e. ATT) comprised of 15 patients in whom anteriorly anchoring flap tympanoplasty was done.

Mean age of patients in our study over all was $25.17 \pm 11.47$ years. CSOM is prevalent in all age groups; however, patients in the paediatric and younger age groups are most commonly affected (WHO, 2004). In a study by Yaor et al, age of patients undergoing myringoplasty ranged from 9 to 84 years with a mean age of 37 years and $24 \%$ of their patients being children aged 9 to15 years. ${ }^{12}$ In present study, mean age was slightly lower which might mainly be attributed to the inclusion criteria where the age range was restricted only between 10 and 60 years. Yoon et al in their series of 111 patients undergoing myringoplasty had all the patients aged 15 years or less. ${ }^{13}$ Magsi et al reported a study in which patients were aged 5 to 50 years and had maximum number of patients aged 11-20 years as against present study in which maximum number of patients were aged 21 to 30 years. ${ }^{14}$ Age has been identified as a possible confounding factor having an impact on the outcome (Webb and Chang) in present study both extreme ends as mentioned in the above studies, were excluded from the study to rule out any such confounding effect. ${ }^{15}$

In present study, majority of patients irrespective of the group to which they were allocated were males. Although some western studies (Webb and Chang) have reported a higher prevalence amongst females yet gender wise differences could be purely incidental and could generally be attributed to gender biased healthcare seeking practices in our settings. ${ }^{15}$

In the study conducted by Kumar et al commonest complaint was observed to be otorrhoea, followed by hearing impairment which is very well with the view of many authors. ${ }^{1}$ Unilateral involvement of ears in the entire study group was seen in $72 \%$ cases while bilateral involvement was seen in $28 \%$ of patients. Out of the unilaterally involved ears, it was seen that left ear was more commonly involved in their study $(58.33 \%)$; in our study also the commonest complaint was ear discharge and the second common complaint being hearing impairment. Similarly in our study $70 \%$ patients had unilateral disease and $30 \%$ had bilateral ear disease which is comparable with their study. While in our study left ear was involved in $67 \%$ which is also comparable with their study.

In our study the mean air bone gap of 8 patients with anterior moderate perforation was $31.75 \pm 7 \mathrm{db}$, for 17 patients with large central perforations was $38.75 \pm 4.88$ $\mathrm{db}$ and for 5 patients with subtotal perforations was $41.4 \pm 3.30 \mathrm{db}$. The mean air bone gap of patients with anterior moderate perforation was significantly low compared to the large and subtotal perforations statistically with $\mathrm{p}$ value of 0.004147 and 0.01051 respectively. While the mean air bone gap when compared between patients with large and subtotal perforation showed no statistical difference ( $\mathrm{p}$ value of 0.17923 which is more than 0.05 ). Terkildsen stated that "There is no general agreement among clinicians about the magnitude and the configuration of the hearing loss that is caused by various types of tympanic-membrane perforations." 16 Shambaugh observed that seemingly identical perforations in size and location produce different degrees of hearing loss. ${ }^{18}$ The reasons for the variations in the hearing effects of simple perforations are not easily defined. Mehta et al in their study concluded that the hearing loss increases with increasing size of a perforation; the hearing loss does not vary substantially with location of the perforation. ${ }^{18}$ Effects of location, if any, are small. Kumar et al also concluded that hearing loss increases with the increase in the size of tympanic membrane perforation. ${ }^{1}$ In our study also patients with anterior moderate perforations had less hearing loss than the large and subtotal perforations which is in accordance with Kumar et al and Mehta et al study.

Technique of underlay tympanoplasty was preferred by us, as it has many advantages, that there is no risk of blunting, lateralization of graft and epithelial cyst formation, as elaborated by Doyle. ${ }^{19}$ Our results and observations about underlay tympanoplasty matches with that of Doyle and Glasscock, where underlay tympanoplasty is justified as a technique with better results. ${ }^{20}$ These findings are in contrast to the results of Rizer, who attained drum healing in $95.6 \%$ in overlay, as compared to $88.8 \%$ in underlay tympanoplasty. ${ }^{21}$ In our study over all we attained drum healing in $90 \%$ with underlay tympanoplasty. While in the individual groups viz STT and AAT we attained drum healing in $93.33 \%$ and $86.67 \%$ respectively. Mishra et al in their study attained drum healing $97 \%$ by doing superiorly based circumferential tympanomeatal flap tympanoplasty (i.e. 
STT technique) which is comparable to our study with 93.33\%. Hosamani et al did 33 patients with anterior tagging myringoplasty (i.e. AAT) showed graft uptake was $95.45 \%$ in anterior and subtotal and concluded with anterior tagging of graft material is a suitable for anterior and subtotal perforations; in our study we attained drum healing in $86.67 \%$ in the group who underwent anteriorly anchoring flap tympanoplasty which is comparable to the above study. ${ }^{23}$ Hence in our study in the individual groups viz STT and AAT we attained drum healing in $93.33 \%$ and $86.67 \%$ respectively, which when compared with each other shows no statistical significant difference ( $\mathrm{p}$ value of 0.5428 which is more than 0.05 ).

In our study the preoperative mean air bone gap of the patients was $37.23 \pm 5.79 \mathrm{db}$ after surgery at 6 months came down to $17.17 \pm 3.31 \mathrm{db}$ hence after calculating the mean air bone gap closure it came down to be 20.4 \pm 4 .85. which showed a significant improvement in the hearing ( $p$ value 1.493 E-23 which is less than 0.05). While in the individual group viz STT and AAT the preoperative mean $\mathrm{AB}$ gap was $38.87 \pm 4.88 \mathrm{db}$ and $35.6 \pm 6.31$ respectively and postoperative at 6 months mean $\mathrm{AB}$ gap was $17.47 \pm 1.96 \mathrm{db}$ and $16.8 \pm 74.32 \mathrm{db}$ respectively. When compared with the preoperative mean air bone gap the postoperative mean air bone gap showed significant improvement. But inter-comparison between STT and AAT of the postoperative mean AB gap at 6 months post-surgery showed no statistical significant difference.

J.F. Sharp et al did 47 cases with anterior or subtotal perforation of pars tensa and found in kerr flap technique graft uptake was $95.7 \%$ and hearing improved by an average $8.5 \mathrm{~dB}^{24}$ Mokhtarinejad et al did 38 cases (group- A) circumferential sub annular grafting and 25 cases (group-B) of underlay tympanoplasty with extension of anterior edge of the graft forward against the lateral wall of the Eustachian tube, they found success rate in $97 \%$ in group A and $100 \%$ in group B patients, improvement of the air conduction thresholds in all frequencies and closure of the mean air bone gap were significant and similar among two groups -A and in group $B$ patients. Mishra et al did prospective study of 100 cases of underlay technique with superiorly based circumferential flap it was found that graft take up was $97 \%$, hearing gain of $10-30 \mathrm{~dB}$ was achieved in $95 \%$ of cases. $^{22}$ In our study the mean air bone gap closure or the hearing gain with the STT and AAT technique was $22.07 \pm 4.15 \mathrm{db}$ and $18.73 \pm 5.05 \mathrm{db}$ respectively which is better than Sharp et al and comparable with the other two studies of Mokhtarinejad et al and Mishra et al.

While comparing the mean air bone gap closure of the patients who got operated by STT and AAT technique at 6 months of surgery it shows that there is no statistical significant difference between both ( $\mathrm{p}$ value of 0.058138 which is more than 0.05 ).
In the study conducted by Mishra et al $7 \%$ patients suffered complications post operatively like otitis media with effusion $(2 \%)$ retraction $(2 \%)$ myringitis $(2 \%)$ and lateralization $(1 \%){ }^{22}$ While in our study 2 patients out of 30 i.e. $6.67 \%$ patients suffered complications of residual perforation which was preceded by acute otitis media, which are comparable to the Mishra et al study. Complications in the individual group i.e. STT and AAT, out of 15 patients of STT group, 1 patient i.e. $6.67 \%$ developed the complication and out of 15 patients of AAT group 1 patient i.e. $6.67 \%$ developed the complication. Comparing the complications in the patients who got operated by STT and AAT technique respectively it showed no statistical significant difference between the two ( $\mathrm{P}$ value of 1 which is more than 0.05 ).

Good hearing gain in our study can be correlated with expertise technique to deal with subtotal perforations with special reference to the superiorly based circumferential tympanomeatal flap and anteriorly anchoring flap placement of the graft, maintaining the conization of the grafted tympanic membrane by placing the graft under the handle of malleus.

Various surgeons have used different kinds of grafts to repair tympanic membrane perforations. Most popular are autogenous grafts. Zollner used pedicled ear canal skin graft to close perforations. ${ }^{26}$ Shea introduced vein graft to close tympanic membrane perforations. ${ }^{27}$ It goes to the credit of Heermann for introducing temporalis fascia as a grafting material in tympanoplasty. ${ }^{28}$ We used temporalis fascia graft to close subtotal perforations and could achieve good results both in terms of drum healing (90\%) and closure of (A-B) gap- of $20.4 \pm 4.85 \mathrm{db}$.

\section{CONCLUSION}

After considering the observations and results and in accordance with the aims and objectives of our study regarding, 'comparison between superiorly based tympanomeatal flap tympanoplasty with the anteriorly anchoring tympanomeatal flap tympanoplasty in large, subtotal, and anterior tympanic membrane central perforations in chronic suppurative otitis media of mucosal type', we conclude that,

1. The graft uptake in large, subtotal, and anterior moderate perforations by each technique is comparable i.e. both techniques have same results in view of graft uptake.

2. The hearing improvement by each of the techniques is comparable i.e. both techniques shows same amount of hearing improvement with no significant difference in patients with large, subtotal, and anterior moderate perforations.

3. Complications produced by each of the techniques are comparable i.e. both the techniques have no significant difference in the complications produced post-surgery. 


\section{Recommendation}

We recommend that both techniques can be used for the repair of large, subtotal, and anterior tympanic membrane central perforations in chronic suppurative otitis media of mucosal type.

\section{Limitations}

Owing to limitation of sample size the trends obtained in present study need further validation and verification

Funding: No funding sources

Conflict of interest: None declared

Ethical approval: The study was approved by the Institutional Ethics Committee of HBT medical college

\section{REFERENCES}

1. Kumar N, Chilke D, Puttewar MP. Clinical Profile of Tubotympanic CSOM and Its Management With Special Reference to Site and Size of Tympanic Membrane Perforation, Eustachian Tube Function and Three Flap Tympanoplasty. Indian J Otolaryngol Head Neck Surg. 2012;64(1):5-12.

2. Frootko NJ. Reconstruction of the ear. In: Kerr AG, Booth JB, editors. Scott Brown's Otolaryngology: Otology. 6th ed. Oxford: Butterworths-Heinnman; 1997;3:1-25.

3. Rafi T. Tympanoplasty in children: A study of 30 cases. J Surg Pak. 2001;6:11:2.

4. Rizer FM Overlay versus underlay tympanoplasty. Part I: historical review of the literature. Laryngoscope. 1997;107(12):1-25.

5. Wehrs RE. Grafting techniques, Otolaryngologic Clinics North Am. 1999;32(3):443-55.

6. Sergi B, Galli J, De Corso E, Parrilla C, Paludetti G. Overlay versus underlay myringoplasty: report of outcomes considering closure of perforation and hearing function. Acta Otorhinolaryngol Ital. 2011;31(6):366-71.

7. Applebaum EL, Deutsch EC. An endoscopic method-of tympanic membrane fluorescein angiography. Annuals Otol Rhinol Laryngol. 1986;95:439-43.

8. Dabholkar JP, Vora K, Sikdar A. Comparative study of underlay tympanoplasty with temporalis fascia and tragal perichondrium. Indian $\mathrm{J}$ Otolaryngol Head Neck Surg. 2007;59(2):116-9.

9. Monsell EM. New and revised reporting guidelines from the Committee on Hearing and Equilibrium. Am Acad Otolaryngol-Head and Neck Surg Foundation, Inc. Otolaryngol Head Neck Surg. 1995;113(3):176-8.

10. Labatut PT, Sierra GC, Mora RE, Cobeta MI. Primary myringoplasties. Results after a 2 year follow-up period. Acta Otorhinolaryngol Esp 2009;60:79-83 .
11. Sergi B, Galli J, De Corso E, Parrilla C, Paludetti G. Overlay versus underlay myringoplasty: Report of outcomes considering closure of perforation and hearing function. Acta Otorhinolaryngol Ital. 2011;31:366-71.

12. Yaor MA, El-Kholy A, Jafari B. Surgical Management of Chronic Suppurative Otitis Media: A 3-year Experience. Annals of African Medicine 2006;5(1):24-7.

13. Yoon TH, Park SK, Kim JY, Pae KH, Ahn JH. Tympanoplasty, with or without mastoidectomy, is highly effective for treatment of chronic otitis media in children. Acta Otolaryngol Suppl. 2007;558:44-8.

14. Magsi PB, Jamro B, Sangi HA. Clinical presentation and outcome of mastoidectomy in chronic suppurative otitis media (CSOM) at a tertiary care hospital Sukkur, Pakistan. RMJ. 2012;37(1):50-3.

15. Webb BD, Chang CY. Efficacy of tympanoplasty without mastoidectomy for chronic suppurative otitis media. Arch Otolaryngol Head Neck Surg. 2008;134(11):1155-8.

16. Terkildsen K. Pathologies and their effect on middle ear function. In: Feldman AS, Wilber LA, editors. Acoustic Impedance and Admittance: The Measurement of Middle Ear Function. Baltimore, MD: Williams \& Wilkins; 1976: 78-102.

17. Glasscock ME, Shambaugh GE. Surgery of the Ear. 4. Philadelphia: Saunders; 1990.

18. Mehta RP, Rosowski JJ, Voss SE, O'Neil E, Merchant SN. Determinants of hearing loss in perforations of the tympanic membrane. Otol Neurotol. 2006;27(2):136-43.

19. Doyle PJ, Schleuning AJ, Echevarria J. membrane. Laryngoscope. 1972;82(8):1425-30.

20. Glasscock ME 3rd, Jackson CG, Nissen AJ, Schwaber MK. Postauricular undersurface tympanic membrane grafting: a follow-up report. Laryngoscope. 1982;92(7):718-27

21. Rizer FM. Overlay versus underlay tympanoplasty. Part II: the study. Laryngoscope. 1997;107(12):2636

22. Mishra P, Sonkhya N, Mathur N. Prospective study of 100 cases of underlay tympanoplasty with superiorly based circumferential flap for subtotal perforations. Indian J Otolaryngol Head Neck Surg. 2007;59:225-8.

23. Hosmani P, Ananth L, Medikeri SB. Comparative study of efficacy of graft placement with and without anterior tagging in type one tympanoplasty for mucosal- type chronic otitis media. J Laryngol Otol. 2012;126(2):125-30.

24. Sharp JF, Terzis TF, Robinson J. Myringoplasty for the anterior perforation :experience with the Kerr flap". J Laryngol Otol.1992;106:14-6.

25. Mokhtarinejad F, Barzegar SARF. Surgical and hearing results of the circumferential sub annular grafting technique in tympanoplasty randomized 
clinical study. Am J Otolaryngol Head Neck Med Surg. 2012;33:75-9.

26. Zollner F. Surgery of malformations of the auditory canal and middle ear. Acta Otolaryngol. 1954;44(56):517-24.

27. Shea, JJ Vein graft closure of ear drum perforation. J Laryngol Otol. 1960;74:358-62.

28. Heermann H. Tympanoplasty with fascial tissue taken from the temporal muscle after straightening the anterior wall of the auditory meatus. HNO.

1961;9:136-7.

Cite this article as: Rathi A, Gite V, Bhargava S, Shetty N. A comparative study of superiorly based circumferential tympanomeatal flap tympanoplasty with anteriorly anchoring flap tympanoplasty in large, subtotal, and anterior tympanic membrane central perforations in chronic suppurative otitis media of mucosal type. Int $\mathrm{J}$ Otorhinolaryngol Head Neck Surg 2018;4:432-9. 